\title{
A importância do trabalho coletivo na gestão dos riscos do/no trabalho em saúde
}

\author{
Josiane dos Santos Patrício \\ Engenharia de Saúde e Segurança formada pela Universidade Federal de Itajubá- Campus Itabira \\ $凶$ eng.josianepatricio92@gmail.com \\ Daniel de Souza Costa Calvo \\ Professor Mestre, do curso de Engenharia de Saúde e Segurança da Universidade Federal de Itajubá- Campus Itabira \\ 凶daniel.souza.costa@hotmail.com \\ Davidson Passos Mendes \\ Professor Doutor, do curso de Engenharia de Saúde e Segurança da Universidade Federal de Itajubá- Campus Itabira \\ 凶davidsonpmendes@gmail.com \\ Geraldo Fabiano de Souza Moraes \\ Professor Doutor, do curso de Engenharia de Saúde e Segurança da Universidade Federal de Itajubá- Campus Itabira \\ $\bowtie$ geraldofsmoraes@gmail.com
}

\begin{abstract}
Resumo:
Esse artigo tem como objetivo identificar as necessidades e possibilidades de antecipação, regulação e as variabilidades presentes na atividade de uma equipe de enfermagem, assim como as estratégias individuais e coletivas que surgem para gerir elementos no contexto de trabalho. A metodologia empregada no estudo tem embasamento na Análise Ergonômica do Trabalho (AET), juntamente com a Ergologia, para aprofundar os conceitos. Os participantes da pesquisa são duas enfermeiras e nove técnicas de enfermagem de um hospital filantrópico de um município do interior de Minas Gerais. Os resultados evidenciaram como a atividade das técnicas de enfermagem é inundada de elementos e é um processo complexo, em que as estratégias e antecipações se mostram fundamentais para o trabalho. Essas estratégias estão associadas ao trabalho coletivo dentro da equipe que, por sua vez, compartilha valores e saberes colocados em prática para gestão dos constrangimentos e variabilidades apresentadas durante a atividade de trabalho, e se tornam primordiais para a conclusão de atendimentos com qualidade e para a manutenção da saúde e segurança de cada trabalhador.
\end{abstract}

Palavras-chave: Ergonomia, Equipe de Enfermagem, Saúde do Trabalhador. 


\title{
The importance of collective work in risk management of health work
}

\begin{abstract}
:
This article had the goal to identify the needs and possibilities of anticipation, regulation and how the variability present in the activity of a nursing team, as well as how individuals and collective strategies arises to manage elements in the work context. The methodology used in the study is based on the Ergonomic Analysis of Work (EAW), together with the Ergology, to deepen the concepts. The research participants are two nurses and nine nursing techniques from a philanthropic hospital of a municipality in the interior of Minas Gerais. The results evidenced how an activity of nursing techniques is flooded with elements and how is a complex process, in which strategies and anticipations are fundamental for the work. These strategies are associated with collective work within the team, that in turn, share values and knowledge put into practice to manage the constraints and variables presented during the work activity, and become fundamental for a conclusion of quality care and for maintenance of the health and safety of each worker
\end{abstract}

Keywords: Ergonomics, Nursing team, Occupational Health.

\section{La importancia del trabajo colectivo en la gestión de los riesgos del / en el trabajo en salud}

\section{Resumen:}

Este artículo tiene como objetivo identificar las necesidades y posibilidades de anticipación, regulación y las variabilidades presentes en la actividad de un equipo de enfermería, así como las estrategias individuales y colectivas que surgen para gestionar elementos en el contexto de trabajo. La metodología empleada en el estudio tiene basamento en el Análisis Ergonómico del Trabajo (AET), junto con la Ergología, para profundizar los conceptos. Los participantes de la investigación son dos enfermeras y nueve técnicas de enfermería de un hospital filantrópico de un municipio en el interior de Minas Gerais. Los resultados evidenciaron cómo la actividad de las técnicas de enfermería es inundada de elementos y es un proceso complejo, en el que las estrategias y anticipaciones se muestran fundamentales para el trabajo. Estas estrategias están asociadas al trabajo colectivo dentro del equipo, que a su vez, comparte valores y saberes puestos en práctica para la gestión de las restricciones y variabilidades presentadas durante la actividad de trabajo, y se vuelven primordiales para la conclusión de atendimientos con calidad y para la mantenimiento de la salud y seguridad de cada trabajador.

Palabras-clave: Ergonomía, Grupo de enfermería, Salud laboral.

\section{INTRODUÇÃO}

No sentido de se analisar a evolução da profissão de enfermagem, podemos observar sua transformação, em que sua história caminha em paralelo com a história da humanidade. 
Como foi dito por Bedin, Ribeiro e Barreto (2005), a análise da profissão de enfermagem pode mostrar seu desenvolvimento pelo passar dos séculos, mantendo uma estreita identificação com a própria história da civilização, exercendo um papel fundamental na promoção do bem-estar das pessoas, levando em conta a sua liberdade, singularidade e dignidade, na promoção da saúde, prevenção de enfermidades, no transcurso de doenças e agravos, nas incapacidades e, até mesmo, no processo de morrer.

Tendo em vista a enfermagem com sua influência e importância no contato direto com pacientes, esses com graus de enfermidades distintos, entrelaça-se a responsabilidade que emana da profissão e o saber lidar com as diferenças do outro, ao mesmo tempo em que se mostra importante um alto grau de humanidade para desempenho das atividades (MENDES, 2018).

Para OLIVEIRA (2001, p.104),

Humanizar, caracteriza-se em colocar a cabeça e o coração na tarefa a ser desenvolvida, entregar-se de maneira sincera e leal ao outro e saber ouvir com ciência e paciência as palavras e os silêncios. $O$ relacionamento e o contato direto fazem crescer, e é neste momento de troca, que humanizo, porque assim posso me reconhecer e me identificar como gente, como ser humano.

Os saberes desenvolvidos pelos profissionais da área vão muito além de conhecimentos agregados em salas de aula. Durante abordagem de pacientes, vários aspectos introduzidos ao profissional por experiências de vida e contatos anteriores com outros pacientes são envolvidos, aspectos como experiências de vida de ambos, os valores de cada um, assim como suas crenças e sentimentos, o modo de vida e a forma de ver o mundo estão presentes e acabam influenciando no sucesso da relação enfermeiro e paciente.

É necessário considerar que essas relações interpessoais se mostram como uma parte do aspecto de trabalho de enfermeiros e técnicos de enfermagem, já que sua rotina é intensa e, muitas vezes, se faz necessária gestão de numerosas ocorrências. É necessário identificar prioridades e colocar em prática o conhecimento para estabilizar ou minimizar a situação.

A equipe de enfermagem está em contato constante com uma pluralidade profissional, médicos, fisioterapeutas, nutricionistas, assistentes sociais, dentre diversos 
outros. Considera-se então sua atividade como uma contribuição para uma somatória de intervenções, sendo todas voltadas para o mesmo propósito, o restabelecimento da condição de saúde do paciente.

Com esses elementos do cotidiano laboral dos enfermeiros e técnicos de enfermagem é observável como a organização do trabalho pode influenciar a saúde e segurança desses profissionais. Como é colocado por David (2009), a forma em que se estrutura uma organização do trabalho de profissionais da área de enfermagem, pode levar ao seu adoecimento, tornando-se um elemento de estudo de estreita relação com a saúde do trabalhador.

Tendo em vista os elementos apresentados nesta introdução que indicam um pouco do ambiente e da organização de trabalho de profissionais da área da saúde e como essa profissão vem se desenvolvendo no decorrer da história, junto com a sociedade, torna-se importante uma análise das condições de trabalho, para identificar medidas que possam levar a melhorias e a manutenção da saúde e da segurança desses profissionais. Uma vez que estruturas de trabalho com grau de nocividade elevado, podem acarretar em um aumento dos riscos, da carga de trabalho, assim como constrangimentos em situação oriunda da atividade. Sendo assim, essa pesquisa tem como objetivo identificar as necessidades e possibilidades de antecipação, regulação e as variabilidades presentes na atividade de uma equipe de enfermagem, assim como as estratégias individuais e coletivas que surgem para gerir elementos no contexto de trabalho.

\section{METODOLOGIA}

Trata-se de um estudo qualitativo. Foram utilizadas a Ergonomia e Ergologia como ferramentas de análises pertinentes para identificar os principais fatores técnicos e organizacionais inferentes sobre os campos de possibilidades de gestão da saúde no trabalho nos contextos produtivos hospitalares.

Em nível da Ergonomia, utilizou-se a ferramenta de verificação - Análise Ergonômica do Trabalho (AET) - como forma de observação para descrição da atividade de trabalho dos 
profissionais de enfermagem, com a perspectiva de evidenciar a atuação dos trabalhadores em situação real de trabalho, com um olhar na relação da tríade: atividade, produção e saúde (GUÉRIN et al., 2001).

A Ergologia também foi utilizada como aprofundamento metodológico. Schwartz e Durrive (2010) afirmam que a análise ergológica é feita tanto quanto possível "do ponto de vista daquele que executa o trabalho" e se constitui no intuito de investigar o permanente debate de normas e de valores que modificam indefinidamente a atividade humana, concentrando-se sobre a relação que é estabelecida com o meio no qual a atividade está engajada.

Foram feitas diversas observações gerais e sistematizadas do campo de estudo (hospital), no setor das enfermarias e os registros foram documentados em diários de campo, com registros fotográficos, gravações de áudios das verbalizações e filmagem das atividades laborais. Foram analisados técnicos em enfermagem e enfermeiros, em seu cotidiano de trabalho, que consentiram em participar voluntariamente da pesquisa, assinando o Termo de Consentimento Livre e Esclarecido (TCLE).

Utilizou-se de entrevistas não estruturadas com os trabalhadores envolvidos na pesquisa, com o intuito de evidenciar o cotidiano de trabalho dos trabalhadores de enfermagem, em momentos adequados e intervalos durante o trabalho, evitando impactos negativos na condução de suas atividades.

Com a população envolvida na pesquisa, empregou-se a autoconfrontação cruzada, tendo o pesquisador papel fundamental para condução de um debate pertinente à atividade em questão. Esse processo ocorreu durante a apresentação de informações, colhidas no posto de trabalho com os trabalhadores exercendo suas funções.

O recorte metodológico dessa pesquisa se estabelece na atividade de trabalho da equipe de técnicos de enfermagem de uma das enfermarias do hospital, sendo essa ala totalmente composta por pacientes provenientes do Sistema Único de Saúde (SUS). A justificativa desse recorte se deve ao fato dessa enfermaria ter o maior quantitativo de leitos e, em razão disso, o maior quantitativo de profissionais dentre as diversas enfermarias do hospital estudado. 
Os pesquisadores obtiveram informações, via diretoria, em um hospital filantrópico de um município de Minas Gerais, no segundo semestre de 2018. O mesmo é referência em traumatologia, maternidade e hemodiálise na microrregião que atua, sendo esta composta por 12 cidades vizinhas, com estimativa total de 300 mil habitantes. Oferece suporte para diversas necessidades clínicas e sua estrutura é composta atualmente por 21 leitos na maternidade, 20 leitos na pediatria, cinco leitos na Unidade Intermediária Neonatal, 78 leitos nas enfermarias destinadas ao SUS, 20 leitos em quartos individuais e 10 Leitos na Unidade de Tratamento Intensivo. $O$ atendimento proveniente de entradas pelo Sistema Único de Saúde representa um total de $60 \%$ dos atendimentos realizados na instituição, demanda essa de maior concentração de leitos, o que ocasiona uma maior demanda de mão de obra nesses setores.

A ala analisada foi definida por critérios de conveniência baseados na demanda estabelecida pela própria instituição estudada, que se caracteriza por a única do hospital onde o acolhimento de pacientes é exclusivamente proveniente do SUS. Possui 40 leitos, distribuídos em 13 quartos, com separação entre homens e mulheres. O período de acolhimento dos pacientes se estabelece por um tempo prolongado, já que os usuários apresentam quadros em que o tratamento hospitalar necessita de um acompanhamento maior, assim como uma realização de medicações constantes. É também a ala responsável pelo atendimento e cuidados referentes a internação de pacientes psiquiátricos. Dessa forma, desses 40 leitos, seis são destinados exclusivamente para esses pacientes, dos quais três são para internos femininos e outros três para masculinos.

Os pacientes podem ser direcionados para a ala por meio de setores distintos do hospital, sendo que os procedimentos de acolhimento, em relação a parte burocrática, também possuem diferenças. Como demonstrado na figura 1 (página seguinte).

A entrada do paciente na estrutura hospitalar pode ocorrer por meio do Pronto atendimento ou Pronto Socorro, após o primeiro atendimento, quando se mostra necessário, ambos os setores podem direcioná-lo ao bloco cirúrgico ou a Unidade de Terapia Intensiva (UTI), que nesse sentido, acabam tornando-se etapas até a ala recorte do estudo.

Este estudo foi aprovado, via Plataforma Brasil, pelos Comitês de Ética em Pesquisa (Proponente e co-participante), sob registros CAAE 75205517.5.0000.5559 e 75205517.5.3001. 5110. 
Figura 1- Estrutura de Acolhimento.

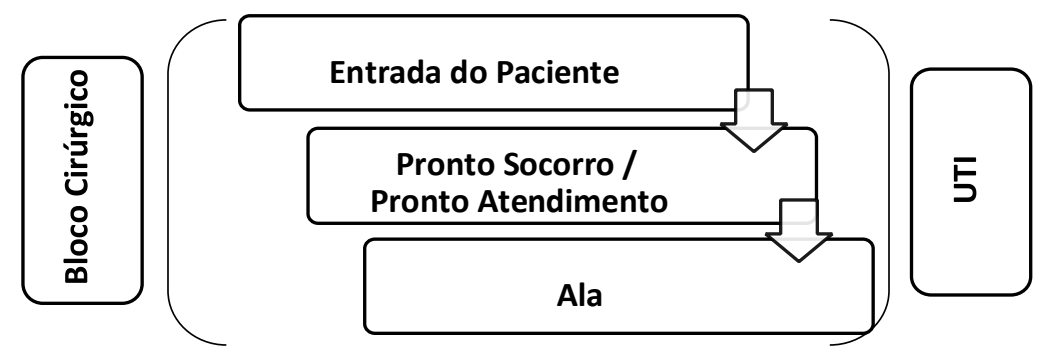

Legenda: Estrutura Organizacional do Setor.

Fonte: AUTORES, 2018.

\section{RESULTADOS E DISCUSSÃo}

A equipe de enfermagem analisada neste estudo era composta de duas enfermeiras e nove técnicas de enfermagem, com tempo de trabalho no hospital variando entre sete meses a 17 anos, sendo as enfermeiras responsáveis pela coordenação da equipe e dos materiais utilizados no atendimento aos pacientes, além de percorrerem os quartos para anamneses e realização de curativos, quando necessário. A jornada de trabalho da equipe é de 12 por 36 horas. $\mathrm{O}$ início das atividades se dá às 7 horas da manhã e se estende até às 19 horas. Apenas o técnico em enfermagem de apoio trabalha no regime de oito horas diárias, de segunda a sexta feira. Essa equipe é constante, sem rodízios. Apenas em caso de férias de membros da equipe ou motivos extraordinários internos do hospital há mudanças. Atualmente a equipe composta somente por mulheres.

Como o setor possui um elevado número de leitos, existem dois ambientes para preparação de medicamentos, denominados de "postinho" um e dois. Cada enfermeira assume um e a equipe de técnicas também é dividida, sendo quatro em cada "postinho" e um como auxílio. Os pacientes internados na ala, como mencionado, ocupam leitos destinados ao atendimento provenientes do SUS e, na maioria das vezes, possuem uma permanência 
com um período de tempo mais elevado, por apresentarem necessidade de acompanhamento médico e monitoramento constante.

Dessa forma, a organização se resume em dois ambientes, tendo em cada, uma enfermeira, quatro técnicas de enfermagem e o técnico de apoio que permanece em ambos. Esse técnico de apoio é responsável por verificar e repor utensílios e materiais necessários para o acolhimento, atendimento e cuidado com os pacientes e também dar suporte aos colegas durante o atendimento.

Cada técnico em enfermagem fica responsável por cinco leitos, independente se existem ou não pacientes internados no leito no presente dia. A cada dia de trabalho um revezamento ocorre, dessa forma toda a equipe percorre cada leito, ou seja, se o técnico 1 está responsável pelos leitos 40 A, 40 B, 40 C, 41 A e 41B, no próximo dia de trabalho ficará responsável pelos leitos $41 \mathrm{C}, 42 \mathrm{~A}, 42 \mathrm{~B}, 42 \mathrm{C}$ e $43 \mathrm{~A}$, e permanece nesse revezamento até percorrer todos os leitos.

Como existem dois quartos com pacientes psiquiátricos, em um total de seis leitos, esse tipo de organização do trabalho garante que nenhum técnico tenha como responsabilidade em um dia de trabalho, o acompanhamento de cinco leitos psiquiátricos, ficando dividido em dois pacientes não psiquiátricos e três psiquiátricos. Como é verbalizado por uma enfermeira.

"Não deixamos nenhuma com cinco leitos psiquiátricos, divide assim, ó: dois não psiquiátricos e três psiquiátricos, no outro dia ela fica com os outros três psiquiátricos e dois não psiquiátricos. Assim não sobrecarrega um, né?".

Verbalização da Enfermeira 1

A Figura 2, a seguir, é um recorte dessa forma de organização de trabalho: 
Figura 2 - Distribuição de Leitos por técnicos

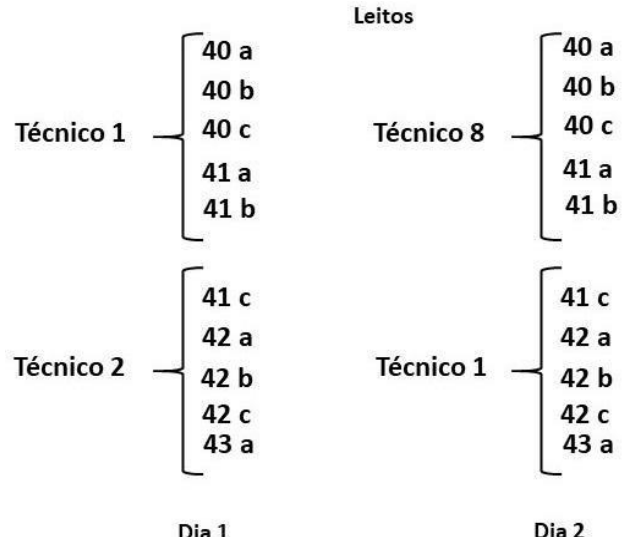

Legenda: Forma que os leitos são distribuídos por profissional. Fonte: AUTORES, 2018.

A equipe que é o foco da presente pesquisa possui as seguintes atribuições, de acordo com o Programa de Prevenção de Riscos Ambientais (PPRA) da empresa:

- Desempenhar atividades técnicas de enfermagem;

- Auxiliar em cirurgia, terapia, puericultura, pediatria, psiquiatria, obstetrícia, saúde ocupacional e outras áreas;

- Prestar assistência ao paciente zelando pelo seu conforto e bem-estar;

- Administrar medicamentos;

- Organizar o ambiente de trabalho, equipamentos e leitos;

- Realizar registros e relatórios técnicos;

- Realizar demais atividades inerentes ao emprego.

\section{Apresentação da Tarefa no nível local de análise}

A forma de organização da tarefa da equipe de enfermagem é feita no nível da Supervisão/Coordenação e quando a notificação de reserva de leitos é feita pelo setor responsável, inicia-se um processo de preparação para o acolhimento, demonstrado na Figura 3, que segue: 
Figura 3 - Fluxo de trabalho na enfermaria analisada.

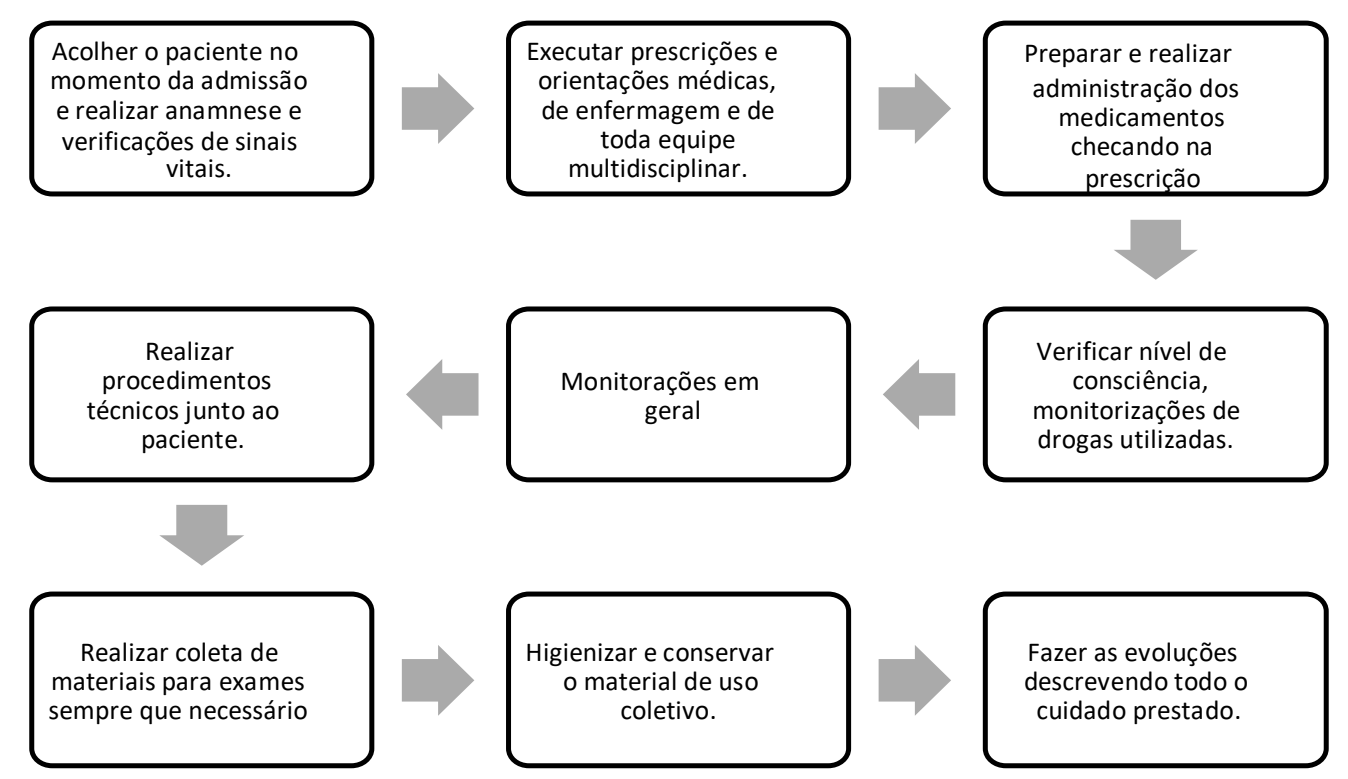

Fonte: AUTORES, 2018.

O trabalho da equipe de enfermagem tem início na admissão do paciente, em que o responsável pelo leito inicia a anamnese e verificação dos sinais vitais do indivíduo, como demonstrado na Figura 4, fazendo anotações das informações colhidas de forma objetiva. Executa as orientações e prescrições médicas e de toda a equipe multidisciplinar. Prepara e desenvolve a medicação de acordo com a prescrição, em constantes monitoramentos referentes ao quadro clínico de cada paciente.

Realiza o deslocamento do paciente, quando necessário, para exames em geral, dentro do próprio hospital, assim como fora do estabelecimento, em clínicas externas. Após o uso de materiais coletivos, durante os banhos de leito, por exemplo, inicia-se uma higienização prévia, para direcioná-los a área de expurgo.

Ao final de cada ciclo de medição e execuções de orientações médicas, as técnicas de enfermagem registram as anotações em um sistema próprio do hospital, todos os cuidados prestados ao paciente. 
Lembrando que esses procedimentos, para a equipe, encerram-se ao final do dia, e podem variar em relação aos cuidados e medicações necessárias de acordo com as prescrições deixadas durante a manhã pela equipe de profissionais multidisciplinares.

Figura 4 - Atendimento a pacientes realizado pelas técnicas.

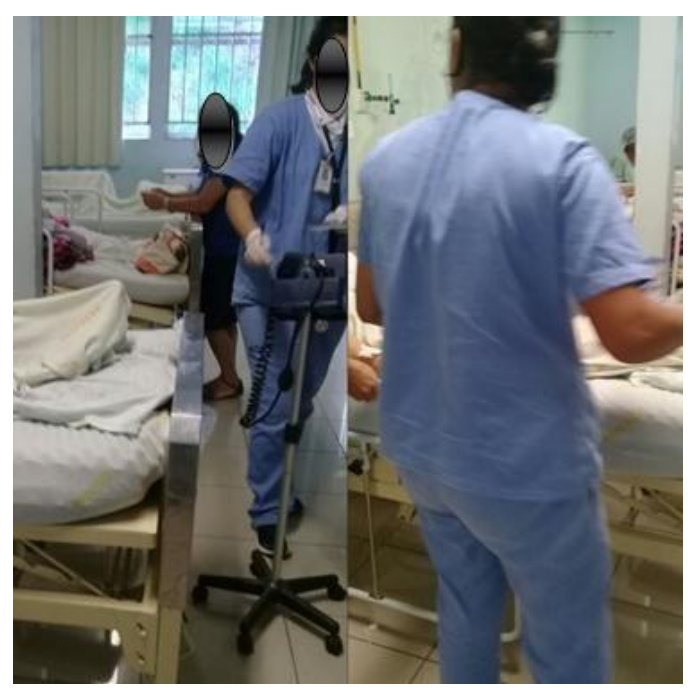

Fonte: AUTORES, 2018.

\section{A atividade de trabalho}

A antecipação de resultados é um reflexo da competência de um profissional e, claro, uma estratégia de regulação (MENDES, 2018), uma vez que, a possibilidade de mensurar os efeitos futuros de decisões e atitudes tomadas no agora, traz a resposta de um trabalho bem feito, antes mesmo da materialização do objetivo (FOSTER et al., 2019).

Essa estratégia vai além de identificar consequências, é uma forma de controlar possíveis desvios e o grau do seu impacto para o trabalho concluído. O cérebro, não se satisfaz em esperar que as informações entrem em contato com ele. Por meio da antecipação dos resultados da ação em curso, ele pode vir a comandar a exploração perceptiva, prognostica as informações que a ação deveria controlar, por amostragem, o que não ocorre como esperado (DANIELLOU; SIMARD; BOISSIÈRES, 2010; YU et al., 2019). 
Uma vez que o trabalho no setor de saúde possui características similares a de prestação de serviços, ou seja, produção e o consumo ocorrendo de maneira simultânea e contínua, a antecipação como foi mencionada, apresenta limitações que estão fora do alcance até mesmo dos mais experientes profissionais da área, já que o resultado está diretamente ligado à resposta do paciente em contato com as abordagens da equipe de enfermagem.

Como é descrito por Moreira (1998), o desenvolvimento de prestação de serviços, restringe um contato muito mais limitado com o cliente, se comparada à atividade industrial, por exemplo. A prestação de um serviço com frequência confunde-se, com o seu consumo. Dessa forma, a prestação do serviço médico, assim como a de enfermagem, dá-se no mesmo instante em que é consumido, ou seja, em que a informação é transmitida ao paciente (SOUZA et al., 2016; MENDES, 2018).

A sincronia na metodologia de produção e consumo do serviço é uma peculiaridade central desse setor e ocorre normalmente com uma co-presença entre trabalhadores e consumidores juntos nos postos de trabalho e na execução das tarefas (ZARIFIAN, 1999; PENA; GOMEZ, 2010, MENDES, 2014; 2018).

Esse lidar de forma dependente à resposta que o paciente transmite pode gerar um cenário de instabilidade para o técnico em enfermagem, essas variabilidades exigem uma maior demanda de modos operatórios e estratégias de regulação, que se tornam elementos primordiais para a conclusão de atividades de atendimento ao paciente de forma segura, eficiente e com qualidade.

Segundo Trierweiller et al. (2008), as variabilidades estão presentes, no que se diz respeito ao intra-individual e no interindividual, igualmente podem estar presentes as variabilidades dos sistemas de organização do trabalho em relação às condições físicas, ambientais e instrumentais.

Sendo que a variabilidade no trabalho é assim um conceito estudado pela Ergonomia e pode ser definida a partir de dois aspectos: a da variação das condições de produção que são ocasionadas das intercorrências intrínsecas ao ambiente de trabalho e, a da variação dos trabalhadores que ocorrem por meio das interações interindividual (diferença entre funcionários) e intra-individual (variação interna de cada um) (PINHO; ABRAHÃO; FERREIRA, 2003; MENDES, 2018). 
A abrangência da competência dos profissionais está ligada à sua habilidade de regulação, então, gerir a variabilidade de acordo com as situações. Quanto mais elevada for a variabilidade nas situações de trabalho, menor a perspectiva de antecipação, fazendo-se necessário dessa forma, uma maior competência dos trabalhadores para a ligação de uma operação prescrita, da tarefa que lhe é dirigida à uma ação situada (contextualizada) (ABRAHÃO, 2000; SOUZA et al., 2016; PEREIRA, 2017; MENDES, 2018).

Mesmo com as limitações apresentadas, pode-se notar essa estratégia de antecipação no momento que a equipe de enfermagem é informada que acontecerá uma internação na ala. O técnico responsável pelo leito onde o paciente permanecerá, já se mobiliza, de acordo com as necessidades dessa pessoa, para que o processo de internação seja realizado de forma rápida e suas funções possam ser desempenhadas dentro do prazo de sua jornada de trabalho. Como é mencionado por uma enfermeira:

“(...) já comunicam com as técnicas, as técnicas vão lá, pede para limpar o leito né? As meninas da...da limpeza, já forra o leito pra aguardar quando o paciente chegar."

Verbalização de uma enfermeira 2.

A invisibilidade de parte do trabalho desempenhado pelos profissionais, pelas técnicas de enfermagem, está nos pequenos detalhes, nas regulações realizadas por elas para entregar o melhor atendimento possível para cada paciente, respeitando suas limitações e peculiaridades.

Existem exames que são realizados em outros setores do hospital, o técnico de apoio é responsável pelo transporte desses pacientes, uma estratégia utilizada é limitar o acesso do paciente ao seu prontuário, durante o caminho entre o leito e o local do exame, sendo que esse percurso é feito por meio da cadeira de rodas ou maca, depende das condições físicas de cada indivíduo. Dessa maneira impede que o paciente ou o acompanhante leia o prontuário e faça conclusões leigas sobre o estado de saúde, levando a nervosismos e inquietudes, podendo gerar um enorme transtorno para quem está responsável pelo transporte. Verbalização feita por uma técnica: 
"Pode até deixar o prontuário no colo dele, né? Mas se perceber que ele está mexendo muito, o acompanhante tá mexendo muito, pede para não fazer isso. Não vão entender o que tá acontecendo direito, vão achar que ele tá morrendo, ai vai ser uma confusão para controlar eles aqui, ai vai ser mais trabalho pra mim."

Verbalização de uma técnica em enfermagem 4.

O constante gerir e antecipar elementos e atividades necessárias, de acordo com as variabilidades, mostra a capacidade e competência do profissional, isso se torna possível pelos saberes desenvolvidos por cada indivíduo da equipe, assim como os saberes gerados de forma coletiva pela equipe. Esses saberes adquiridos por meio do contato com a atividade, é relevante e se torna primordial para a qualidade do trabalho realizado.

O indivíduo, na condução de suas funções, não consegue se limitar ao uso contínuo e submeter-se plenamente às imposições do que é apresentado pelo prescrito. Essa forma de condução do trabalho, além de ser impraticável, pode acarretar danos graves para a saúde do mesmo. Trabalhar é gerir. Não há como a vida se desenrolar sob o registro da estrita heterodeterminação, do assujeitamento ao meio. Submeter-se inteiramente às normas seria invivível, como nos é colocado por Schwartz e Durrive (2010).

Como é apontado por Abrahão (2000), fazer o reconhecimento e ter a compreensão da variabilidade individual nas diversas etapas de um projeto industrial/organizacional, assim como no contexto de trabalho, possibilita a introdução de elementos flexíveis desde a concepção como, por exemplo, a valorização de um saber constituído ao longo do tempo, incorporado na experiência do trabalhador.

A invisibilidade do profissional está nos detalhes que vão além da tarefa, está ligado a forma de gerir os recursos e no cuidado individualizado para cada paciente, respeitando suas características e história de vida.

O trabalho prestado pelas técnicas vai além do que está no prescrito, vai além do que está nos prontuários e nas orientações médicas passadas, isso é apenas um suporte, uma base, já que o trabalho real é inundado de incertezas e de elementos que somados compõem uma estrutura de cuidado e carinho para com cada paciente, de maneira que esse não se limite a receber apenas os medicamentos e, sim, doses de afeto e atenção, também.

Durante a passagem do médico plantonista, as técnicas muitas vezes priorizam atendimentos à pacientes que apresentam pioras nos quadros clínicos, necessitando de 
encaminhamento para a UTI, ou pacientes que mostram sinais evidentes de melhoras podendo receber alta. Essa priorização ocorre, uma vez que o profissional que mais tem contato com cada pessoa hospitalizada são as técnicas de enfermagem, no agrupamento dos prontuários, deixando com mais evidência ou deixando no topo do monte de prontuários.

Como é possível observar na Figura 5, que representa uma observação das atividades desempenhadas por uma técnica, sendo que o tempo gasto por cada uma foi cronometrado. A técnica em questão foi escolhida por verbalizar que no determinado momento ela estava tranquila com suas atividades.

É possível notar que mais de $16 \%$ do tempo gasto nas atividades laborais cotidianas dos profissionais de enfermagem, foi em função de debates pertinentes a assuntos relacionados a pacientes, como seus quadros clínicos e emocionais com equipes envolvendo médicos, outros enfermeiros e técnicos. 0 restante do tempo foi em atividades como conferência de medicação, preparo da mesma, atendimento a pacientes, organização do prontuário (onde entram todas as manobras feitas com pacientes) e repasse das informações para o prontuário eletrônico, denominada evolução realizada pelas enfermeiras e anotação, pelas técnicas de enfermagem. Existem ainda quase $2 \%$ de suporte oferecido a colegas de trabalho.

Figura 5 - A (in)visibilidade do trabalho de um técnico em enfermagem

\begin{tabular}{llccc}
\hline \multicolumn{1}{c}{ ATIVIDADES REALIZADAS } & $\begin{array}{c}\text { TEMPO } \\
\text { (Seg.) }\end{array}$ & $\begin{array}{c}\text { TEMPO } \\
\text { (Min.) }\end{array}$ & \% \\
\hline 1. & $\begin{array}{l}\text { Discussão sobre pacientes com equipe } \\
\text { médica }\end{array}$ & 328 & 5,47 & $3,03 \%$ \\
2. & Discussão sobre pacientes com equipe de & 1422 & 23,70 & $13,12 \%$ \\
Enfermagem & Deslocamento entre Setores & 0 & 0,00 & $0,00 \%$ \\
4. & Atendimento aos Pacientes & 4702 & 78,37 & $43,38 \%$ \\
5. $\begin{array}{l}\text { Anotações e organização de prontuários e } \\
\text { prontuários Eletrônicos }\end{array}$ & 851 & 14,18 & $7,85 \%$ \\
6. Solicitação de Recursos em outros Setores & 668 & 11,13 & $6,16 \%$ \\
7. $\quad$ Contenção de Pacientes psiquiátricos & 1539 & 25,65 & $14,20 \%$ \\
8. & Preparando Material para medicação. & 1036 & 17,27 & $9,56 \%$ \\
9. Suporte a colegas. & 213 & 3,55 & $1,97 \%$ \\
10. & Outros & 79 & 1,32 & $0,73 \%$ \\
& Total: & 10838 & 180,63 & $100,00 \%$ \\
\hline
\end{tabular}




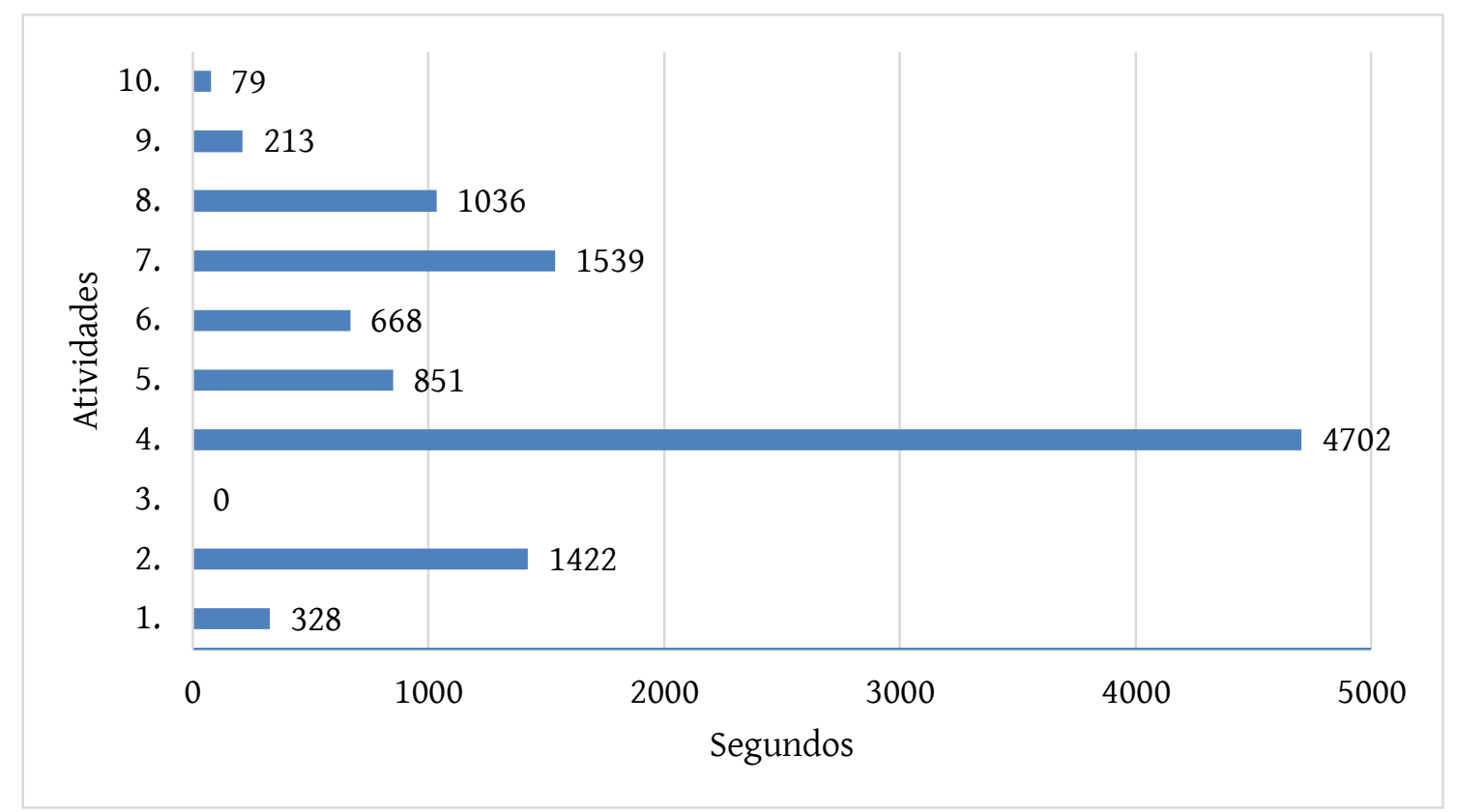

Fonte: AUTORES, 2018.

O objetivo do gráfico apresentado na Figura 5 é mostrar como um período de tempo contínuo e "tranquilo", segundo a técnica, é inundado de antecipações e troca de saberes entre os profissionais envolvidos, em uma constante performance para gerir sua própria atividade e fornecer um trabalho de qualidade. Os valores ali envolvidos se deram em razão, principalmente, da qualidade da assistência ao paciente.

Ainda na Figura 5, existe um percentual de $14 \%$ que representa a tentativa de contenção física de um paciente psiquiátrico, onde a enfermeira está como suporte para outras técnicas, já que essa atividade não pode ser feita sozinha, uma vez que por afirmação delas é extremamente difícil e arriscado. De acordo com o nível de agitação, esses pacientes podem representar um risco para a integridade física dos profissionais da área de saúde, assim como para si mesmos e os outros pacientes (MANTOVANI et al., 2010; MENDES, 2014; 2018).

A formação de um coletivo nesse ambiente é necessária, o vínculo de atenção e cuidado de cada profissional com seu trabalho, com o bem-estar do seu paciente também se mostra efetivo com o trabalho e o paciente das outras técnicas. $\mathrm{O}$ isolamento dificultaria e limitaria manobras fundamentais para as tarefas passadas, principalmente, quando a atividade está ligada a pacientes psiquiátricos, "o trabalho em saúde é necessariamente coletivo e se estrutura nas Entidades Coletivas Relativamente Pertinentes (ECRP)" (MENDES, 2014, p.148). 
Ainda segundo Mendes (2014), se o coletivo não estiver em sintonia, riscos no trabalho passarão a existir, sendo que com isso, o hospital, os trabalhadores e pacientes serão afetados negativamente.

Abrahão (2000) coloca que assim como as estratégias individuais, os funcionários concretizam estratégias coletivas que são desenvolvidas graças ao compartilhamento do objeto de seu trabalho com os colegas.

Uma estratégia coletiva se apresenta no banho de leito, onde pacientes mais debilitados necessitam de serem limpos em suas camas. Ao invés de apenas uma técnica realizar o procedimento, já que a norma coloca uma técnica por leito, duas ou mais o fazem, de forma que o trabalho seja concluído mais rápido e o incômodo e a dor do paciente durem menos. Uma técnica verbaliza:

"Quando aperta, uma ajuda a outra, pra andar rápido. Pega duas em cada um (paciente), pega até três quando precisa, ai é melhor pra acaba e melhor pra ele também."

Verbalização de uma técnica em enfermagem 2.

Schwartz e Durrive (2010) enfatizam que: “Trabalhar é gerir. Submeter-se inteiramente as normas é invivível". Padronizar as normas é impossível. O trabalhador necessita de constantes renormatizações e fazer usos de saberes e competências que vão além da prescrição, fazer uso do corpo si.

Para Schwartz (2001, p. 664) apud Mendes (2014, p. 161):

O corpo si é história, história como memória sedimentada, organizada na miríade dos circuitos da pessoa; mas também história como matriz, energia produtora de inédito: na medida em que a ambição renormatizante é ao mesmo tempo imposta ao ser [...] e também demandada como exigência de vida, como apelo nele próprio da saúde, instrumentando-o sem cessar para tentar transformar o que é objetivamente para ele meio [...] naquilo em que poderia constituir seu meio.

Ainda durante uma contenção física de pacientes psiquiátricos, em crise de abstinência por uso de múltiplas drogas, o coletivo se apresenta forte, independente da 
função de cada profissional ou setor de trabalho. Todos sem prévia discussão ou repasse de tarefas, identificam a melhor forma de agir para conter a situação em curso. Como demonstrado nas verbalizações:

“No dia que ele surtou, foram oito prá lá, a D. ${ }^{1}$ correu pra pegar a contenção pra amarrá, né? Nisso o menino da outra ala já chegou junto com todo mundo daqui, e tinha que fazer, por que ele estava agarrado no cabelo da enfermeira e nada tirava, né?"

Verbalização de uma Técnica 3.

"Pra conter quando eles estão nervosos mesmo, a gente faz assim, um pega o braço, assim né, outro pega a perna, seguram também o corpo até amarrar. Quando ele fica de pé tem que fazer diferente lá, costuma que umas segura os braços, o pessoal da outra Ala já vem também, pra deitá passa a perna aqui nele (pés e canela), quando ele desequilibra já vai caindo na cama e ai é segurar."

Verbalização de uma Técnica 5.

Essas estratégias não estão contidas nas normas e regras, sendo assim, Oliveira, Alvarez e Brito (2013) colocam que toda atividade é reprocessamento de normas, e, dessa forma, oportunidades de agregar novos saberes, pondo-os em espera de serem utilizados. A atividade vem com um debate de normas, com uma atualização das normas antecedentes devido ao modo que cada indivíduo reinventa o seu improvisar em diversos usos de si.

O valor dado ao trabalho pelos profissionais analisados se mostra aparente, principalmente quando o assunto é bem-estar de cada pessoa hospitalizada. Durante uma troca de turno foi possível registrar a seguinte verbalização de uma técnica para sua colega:

“O senhor do 46 A está reclamando muito de dor, mas num é dor não, ele quer atenção, tá sozinho lá, sempre que der cê vai lá e leva água pra ele e diz que é remédio, aproveita e conversa um pouco, ele vai ficar melhor."

Verbalização de uma técnica em enfermagem 2.

Para Schwartz (2014), as renormatizações são oriundas de arbitragens, sendo essas arbitragens, um debate constante das normas. Dessa forma "ocorre continuamente algo

\footnotetext{
${ }^{1}$ D. é a inicial do nome de uma das funcionárias da equipe de Serviços Gerais do Hospital.
} 
novo" que, os fazem escolher sempre baseados nos seus saberes e valores. Com isso o sujeito vive uma "dramática do uso de si" devido às micro escolhas às quais ele deve tomar.

O trabalho é lugar de uma distância inevitável entre o prescrito e o real, portanto, lugar de acontecimentos complexos, marcado por decisões instruídas para preencher estas lacunas. A atividade se engendra nessa porosidade do prescrito, em seus interstícios como micro decisões. Ela é conduta industriosa, decisão julgamento orientado por critérios; arbitragem baseada em valores (CUNHA, 2007).

Os valores podem basear os trabalhadores para que façam escolhas, e isso é devido ao debate de normas, que pode se dar nas normas antecedentes (saberes estabilizados e protocolares e saberes da experiência dos trabalhadores), e as normas e procedimentos internos das organizações).

No ambiente de trabalho analisado existem momentos de constrangimentos durante a atividade, quando o técnico está no dia de ficar com leitos psiquiátricos e não psiquiátricos, e entre esses existem pacientes com crise de abstinência, sua percepção de risco muda, assim como suas regulações e estratégias devem ser condizentes com as formas distintas de trabalhar que se apresentam.

"Quando tenho "normal" e psiquiátrico fico mais cansada, porque tenho que olhar um calmo e tranquilo aqui e já no mesmo momento ficar de olho, atenta com o de cá para não levar nada na cara né? Cê já viu né? Então a cabeça vai a mil. Fico mais estressada."

Verbalização de uma técnica em enfermagem 4.

Isso influencia no bem-estar do trabalhador e, consequentemente, na qualidade do trabalho prestado, uma vez que o mesmo não pode, segundo a verbalização, desligar-se totalmente para cada atendimento, tem que atender, mas sempre pensando no outro leito e em suas complicações.

Uma forma que elas encontraram, de maneira não formal, mas sim uma organização informal de trabalho, foi a formação de uma ECRP, para casos de surtos com os psiquiátricos, onde de forma natural e organizada todas, em casos de intercorrências, já sabem como se 
posicionar e como auxiliar as demais para que o paciente possa ser contido e todas permaneçam seguras.

As ECRP mostram como existem cooperações no ambiente de trabalho, a análise da atividade com suas singularidades pode revelá-la. Dessa forma a definição de uma equipe não pode se restringir como algo rígido, pois, o trabalho coletivo se constrói de acordo com a necessidade no momento da atividade (SCHERER; PIRES; SCHWARTZ, 2009).

Como é colocado por Mendes (2014, p. 144):

Revela-se o agir competente como estratégia de gestão no trabalho. Houve uma apropriação das normas antecedentes associadas ao histórico e à singularidade da ação situada baseada em valores dimensionáveis e não dimensionáveis. Essa gestão refletida aqui como individual, mas instaurada coletivamente nas ECRP, dimensiona a gestão de leitos, qualidade da assistência e clínica a ser estabelecida, além da gestão de saúde e segurança.

Com o que foi apresentado é possível perceber como o trabalho, a atividade das técnicas de enfermagem é inundada de elementos e é um processo complexo, principalmente por causa dos constrangimentos e das inúmeras variabilidades que apresentam limitações de antecipação, e a forma como esse trabalho é conduzido e as estratégias utilizadas mostram a competência de cada profissional e os saberes e valores coletivos e individuais que despontam para com a sua atividade.

É importante colocar como o trabalho coletivo é fundamental para o dia a dia de trabalho, já que as estratégias coletivas são primordiais para a conclusão de atendimentos com qualidade e para a manutenção da saúde e segurança de cada trabalhador.

\section{CONSIDERAÇÕES FINAIS}

É importante colocar que as atividades desenvolvidas vão muito além do descrito na tarefa, e mesmo que as antecipações sejam limitadas devido a necessidade de resposta dos pacientes. As técnicas, em sua invisibilidade, realizam diversas tomadas de decisões baseadas 
em seus conhecimentos, saberes e valores, assim como os de seus pares, enfermeiras e corpo médico.

As estratégias coletivas de regulação estão presentes em vários aspectos, principalmente quando se apresenta a necessidade de contenção física de pacientes psiquiátricos em crises de abstinência - fundamental para garantir a saúde e segurança dos profissionais e qualidade no atendimento.

Uma vez que o coletivo se mostra fundamental no decorrer da atividade, é importante gerar uma promoção de espaços organizacionais para debates e troca de experiências entre funcionários, visando uma integração assim como meio para o desenvolvimento de parcerias internas e conhecimentos necessários para atividades.

Os pacientes psiquiátricos em crise se tornam um risco eminente para o profissional de enfermagem, assim como fator de elevação da carga de trabalho e estresse, apresentandose dessa maneira uma necessidade de mudanças na forma de distribuição de leitos por profissional. o problema não é o paciente psiquiátrico, seu potencial risco, mas a necessária construção de estratégias individuais e coletivas para lidar com esse paciente (processos de produção e atualização de saberes). Ao se estabelecer rodízio de leitos e de perfis de pacientes cria-se um risco desnecessário e aumenta a carga de trabalho, além de desconfigurar o coletivo, necessário para a montagem de uma ECRP. Uma estratégia para minimizar os impactos seria a redução do número de leitos para profissionais que tenham que lidar com os psiquiátricos e o atendimento específico a eles (fomentar o agir competente), sem rodízio.

Como limites desse estudo pode-se apontar a dificuldade de coleta de dados por meio de gravações do trabalho no momento da execução, uma vez que tal ato poderia colocar os pacientes em situação de desconforto e riscos.

Dessa maneira, é importante a realização de outras pesquisas com essa problemática em outros contextos da atividade de trabalho da equipe de enfermagem a fim de comparação de resultados. É importante fazer revelar a invisibilidade da atividade de trabalho dessa população para que se possa fazer evoluir as prescrições e o padrão normativo por meio da atividade. Muito do que se faz, e como fazem, é desconhecido pelos gestores dos diversos sistemas de saúde, impactando nas (in)possibilidades de manutenção da saúde e segurança do próprio trabalhador e do paciente). 


\section{REFERÊNCIAS}

ABRAHÃO, J. I. Reestruturação produtiva e variabilidade do trabalho: uma abordagem da ergonomia. Psicologia: teoria e pesquisa, v.16. n.1, p. 49-54, 2000.

BEDIN, E.; RIBEIRO, L. B. M.; BARRETO, R. A. S. S. Humanização da assistência de enfermagem em centro cirúrgico. Revista Eletrônica de Enfermagem, v. 07, n. 01, p. 118 - 127, 2005.

CUNHA, D. M. Notas conceituais sobre atividade e corpo si na abordagem ergológica do trabalho. Reunião Anual da Associação Nacional de Pós-Graduação e Pesquisa em Educação, v. 30, 2007

DANIELLOU, F.; SIMARD, M.; BOISSIÈRES, I. Fatores humanos e organizacionais da segurança industrial: um estado da arte. Traduzido por: ROCHA, R; LIMA, F; DUARTE, F. Facteurs Humains et Organisationnels de la Sécurité Industrielle. Cadernos da Segurança Industrial, Toulouse, França (2010).

DAVID, H. M. S. L.; MAURO, M. Y.; SILVA, V. G.; PINHEIRO, M. A.; SILVA, F. H. Organização do trabalho de enfermagem na atenção básica: uma questão para a saúde do trabalhador. Texto Contexto Enferm, v. 18, n. 2, p. 206-14, 2009.

FOSTER, K.; ROCHE, M.; DELGADO, C.; CUZZILlO, C.; GIANDINOTO, J. A.; FURNESS, T. Resilience and mental health nursing: An integrative review of international literature. International Journal of Mental Health Nursing, v. 28, n. 1, p. 71-85. 2019.

GUÉRIN, F.; LAVILLE, A.; DANIELLOU, F.; DURAFFOURG, J.; KERGUELEN, A. Compreender o Trabalho para Transformá-lo: a Prática da Ergonomia. 1 ed. São Paulo, Editora Edgard Blücher, 2001.

MANTOVANI, C.; MIGON, M.; ALHEIRA, F.; DEL-BEN, C. Manejo de paciente agitado ou agressivo. Revista Brasileira de Psiquiatria, v. 32, n. suppl 2, p. S96-S103, 2010.

MENDES, D. P. O agir competente como estratégia de gestão do risco de violência no trabalho: o ponto de vista da atividade humana do trabalho dos técnicos de enfermagem de uma instituição pública psiquiátrica. 2014. Tese (Doutorado) - Universidade Minas Gerais; Belo Horizonte, 2014.

MENDES, D. P.; CUNHA, D. M. La opacidad del trabajo de enfermería y las configuraciones del riesgo. Salud colectiva, v. 14, p. 725-742, 2018.

MOREIRA, D. A. Produção e Operações. São Paulo: Pioneira, 1998.

OLIVEIRA, M. E. Mais uma nota para a melodia da humanização. In: OLIVEIRA, M. E.; ZAMPIERI, M. F. M; BRUGGEMANN, O. M. A melodia da humanização: reflexos sobre o cuidado durante o processo do nascimento. Florianópolis. Ed. Cidade Futura, 2001.

OLIVEIRA, S.; ALVAREZ, D.; BRITO, J. A dimensão gestionária do trabalho: aspectos da atividade de cuidado. Ciência \& Saúde Coletiva, v. 18, n. 6, 2013.

PENA, P. G. L.; GOMEZ, C. M. Premissas para a compreensão da saúde dos trabalhadores no setor serviço. Saude soc. [online], v.19, n.2, p.371-383. 2010.

PEREIRA, A. C. E; MENDES, D. P.; MORAES, G. F. S. Do prescrito ao real: a imprevisibilidade e a importância do trabalho coletivo em um centro de usinagem de uma empresa metal-mecânica do interior do Estado de Minas Gerais. Laboreal, v. 13, n. 1, p. 24-38, 2017.

PINHO, D. L. M.; ABRAHÃO, J. I; FERREIRA, M. C. As estratégias operatórias e a gestão da informação no trabalho de enfermagem, no contexto hospitalar. Rev. Latino Am Enfermagem, v.11, n.2, p. 168-176, 2003.

SCHERER, M. D. A.; PIRES, D.; SCHWARTZ, Y. Trabalho coletivo: um desafio para a gestão em saúde. Revista de Saúde Pública, v. 43, n. 4, p. 721-725, 2009. 
SCHWARTZ, Y.; DURRIVE, L. Trabalho e Ergologia: conversas sobre atividade humana. 1.ed. Niterói: Ed UFF, 2010.

SOUZA, G. C.; PEDUZZI, M.; SILVA, J. A. M.; CARVALHO, B. G. C. Trabalho em equipe de enfermagem: circunscrito à profissão ou colaboração interprofissional? Revista da Escola de Enfermagem da USP, v.50, n.4, p. 642-649, 2016.

SCHWARTZ, Y. Motivações do conceito de corpo si: corpo si, atividade, experiência. Letras de Hoje, v. 49, n. 3, p. 259-274, 2014.

TRIERWEILLER, A. C.; AZEVEDO, B. M.; PEREIRA, V. L.; CRUZ, R. M.; GONTIJO, L. A.; JUNIOR, R. L. A estratégia operatória utilizada pelos trabalhadores e o hiato existente entre o trabalho prescrito e o trabalho real. Revista Gestão Industrial, v. 4, n. 1, 2008.

YU, F.; RAPHAEL, D.; MACKAY, L.; SMITH, M.; KING, A. Personal and work-related factors associated with nurse resilience: A systematic review. International Journal of Mental Health Nursing, v. 93, p.129-140, 2019.

ZARIFIAN, P. Objectif compétence. Paris: Liaisons, 1999.

\section{(c))EY}

Este trabalho está licenciado com uma Licença Creative Commons - Atribuição 4.0 Internacional. 